\title{
INFLUENCE OF ABIOTIC DISORDERS ON NUTRITIONAL VALUES OF TOMATO (SOLANUM LYCOPERSICUM)
}

\author{
László Csambalik', Anna Divéky-Ertsey ${ }^{1}$, Márta Ladányi $^{2}$, Csaba Orbán ${ }^{3}$ \\ ${ }^{1}$ Corvinus University Budapest, Horticultural Faculty, Department of Ecological and \\ Sustainable Production Systems, 1118 Villányi út 29-43, Budapest, Hungary \\ ${ }^{2}$ Corvinus University Budapest, Horticultural Faculty, Department of Biometrics and \\ Agrarinformatics, 1118 Villányi út 29-43, Budapest, Hungary \\ ${ }^{3}$ Semmelweis University, Faculty of Health Sciences, Department of Dietetics and Nutrition \\ Sciences, 1088 Vas u. 17. Budapest, Hungary \\ e-mail: laszlo.csambalik@uni-corvinus.hu
}

\begin{abstract}
Susceptibility to abiotic disorders could play a key role in the utilization of landraces of tomato. These races have been abandoned due to non-compatibility to today's intensive agriculture. As there is dissatisfaction on present varieties and hybrids in the context of flavor and nutritional value, landraces could be a viable alternative for the enhancement of these parameters either "per se" or as breeding background. However, frequent occurrence of abiotic disorders causes yield losses. The hypothesis of the present study is that removal of irregular fruit parts positively influences the nutritional profile of tomato in the context of investigated parameters.

In the present study influence of abiotic disorders on total soluble solids (TSS), acid (TA) and lycopene content was investigated on six Hungarian tomato landraces and two commercial varieties. Abiotic disorders occurred were mainly cracking, green shoulder, sunburst and catfacing. Propagation materials were provided by Plant Biodiversity Center Tápiószele. The experiment is supported by Research Institute of Organic Agriculture, ÖMKi.

Our results showed that abiotically disordered plant parts have an impact on TSS, TA and lycopene content, however, in case of investigated accessions and varieties the difference was seldom significant. Only in case of TSS a tendency can be experienced, where all samples showed lower results after the removal of abiotically disordered plant parts. In case of TA and lycopene content no tendencies could have been withdrawn.
\end{abstract}

Keywords: tomato, abiotic disorders, landrace, nutritional values, lycopene

\section{INTRODUCTION}

Tomato is one of the most frequently consumed vegetables due to its valuable nutritional contents and versatility (Abushita, 1997). Its effect against certain types of cancers and cardiovascular diseases is likely to be justified mainly due to its carotenoid content (Giovannucci, 1999).

As there is a dissatisfaction on the flavor of present tomato varieties experienced (Powell et al, 2012), landraces comes back to light as considered as having better taste (Casals et al, 2011). Taste is mainly defined by the ratio of total water soluble solids (TSS, sugars) and acid content (TA) of tomato (Stevens, 1977). Flavor intensity, the multiplication of TSS and TA can provide further (Rodríguez-Burruezo, 2005) information about flavor.

Most of abiotic disorders are genetically encoded and less dependent on environmental factors (Male, 1999); due to breeding efforts of the last decades novel tomato varieties are round, deep red and firm without any notable deformation. 
Half of dry matter content is given by reducing sugars in tomato. Both glucose and fructose is allocated in locular content and walls as well with a slightly higher amount in the latter. Acid content is mainly given by citric and malic acids in tomato. Two third of acid levels is located in the locular contents, while one third of them is found in the pericarp. Lycopene is a carotenoid in tomato providing the red color of the fruit. Most of this pigment is stored in the pericarp of tomato (Davies and Hobson, 1981). Based solely on literature one could expect that when removing parts of pericarp of an intact tomato fruit, slight decrease in sugar levels, increase in acids and notable decrease in lycopene is observed. However, nutritional content of disordered fruit parts has only been investigated indirectly.

\section{MATERIALS and METHODS}

\section{Materials}

Propagation materials of the investigated seven landraces and one old variety were provided by Plant Biodiversity Center Tápiószele. The number, catalogue number, origin or name and average fruit weight of accessions are listed in Table 1. Production of selected traits was designed at the organically certified experimental field of Corvinus University Budapest, Dept. of Ecological and Sustainable Production Systems. Open field conditions were supported with drip irrigation and agrotextile soil coverage.

Landraces of the trial are of two types with different fruit characteristics. Salad type has an elongated fruit shape with a pointed blossom end. It has a high flesh consistency with a low number of locules, which is explicitly weak in seeds and placental tissue as well. Typical abiotic disorders are radial cracking, green shoulder and blossom end rot. This type is ideal for salad and for decoration.

Canning type has a bigger fruit size with multiple locules surrounded with thick walls. Mature fruits are hard to transport due to their soft structure; ideal for canning due to its fleshy structure and sweet taste. Typical abiotic disorders are radial and concentric cracking, scars, catfacing (irregular blossom end closing), green shoulders and sunscald.

Table 1 Catalogue number, origin, fruit shape and average fruit weight of investigated accessions and varieties

\begin{tabular}{|l|l|l|l|}
\hline No. & Catalogue no. & Origin/name & Fruit shape \\
\hline \multicolumn{3}{|l|}{ Salad type } \\
\hline 11 & RCAT031255 & Soltvadkert & Elongated \\
\hline 20 & RCAT060349 & Nagykáta & Elongated \\
\hline \multicolumn{2}{|l|}{ Canning type } & \\
\hline 8 & RCAT031091 & Pácin & Flattened \\
\hline 15 & RCAT057664 & Kaskantyú & Flattened \\
\hline 16 & RCAT057830 & Kóka & Flattened \\
\hline 19 & RCAT060348 & Nagykáta & Oxheart \\
\hline 21 & n.a & Tápláni konzerv & Slightly flattened \\
\hline 24 & n.a & Marmande & Flattened \\
\hline
\end{tabular}

\section{Methods}

For the instrumental measurements two fractions of $500 \mathrm{~g}$ of fruit have been separated in case of each race or variety. Sampling was done on 14 August 2012 after collecting marketable fruits of each trait.

After weighing all of the damaged parts have bee removed from the fruits of the first fraction then homogenized by a laboratory homogenizer for 30 seconds with no dilution, while the 
other fraction was homogenized without removing any disordered parts. The edible fraction was weighed after removal of damaged parts as well and cleaning losses have been calculated and expressed in percentage.

The amount of total soluble solids (TSS) was measured with a Hanna Instruments HI 96801 type digital refractometer expressed in BRIX ${ }^{\circ}$ Total acidity (TA) was measured by titration with $0.1 \mathrm{M} \mathrm{NaOH}$, and expressed in a citric acid equivalent percentage.

Lycopene content determination was performed as described by Ravelo-Pérez et al. (2008), samples were extraceted by solvent containing aceton (with $0,05 \% \mathrm{BHT}$ ), ethanol and hexane mixture. Supernatant were measured against $\lambda=503 \mathrm{~nm}$, and lycopene content was expressed in $\mathrm{mg} / 100 \mathrm{~g}$ dimension.

Each instrumental measurement was performed in three replicates.

TSS/TA ratio was calculated by dividing TSS by TA. Flavor intensity (FI) equals to the multiplication of TSS and TA.

Two way analysis of variance model was run with fixed factors variety and treatment (i.e. the damaged part was removed or not). The normality of the residuals was proved by d'Agostino's test while the homogeneity of variances was tested by Levene's test ( $>00.05)$. In case of significant ANOVA result, Tukey's or Games-Howell's post hoc test was run, according to the Levene's test result. The statistical analysis was conducted by IBM SPSS Statistics ver. 20.

\section{RESULTS and DISCUSSION}

Cleaning losses of each race or variety were expressed in percentage. A loss of 25-45 percent were registered in case of investigated varieties. Most of the races showed losses around 30 percent, except landrace No. 16 with almost 45 percent loss, which seems to be unacceptable for a grower. The lowest loss $(26 \%)$ was measured in case of landrace No. 19. Commercial varieties no. 21 and 24 gave not outstanding but average results.

With regards to TSS, the effect of both factors varieties and treatment was significant $(\mathrm{F}(7 ; 38)=111.6 ; \mathrm{p}<0.001 ; \mathrm{F}(1 ; 38)=13.29 ; \mathrm{p}<0.01)$ with insignificant interaction (Figure 1). The highest results were shown by salad types no. 11 and 20, respectively. The former had significantly higher levels in both treatments. Lowest results were shown by commercial varieties no. 21 and 24, having the latter significantly lower results from all landraces in both treatments. In case of all accessions and varieties cleaning increased TSS content, except in case of no. 8, where no difference was observed. It suggests that the disoredered fruit part which has been removed -e.g. green shoulders, scars and sunscalded spots- contains relatively less solids within the fruit.

With regards to the total acid content (Figure 2), we detected that the effect of varieties is significant $(\mathrm{F}(7 ; 38)=34.13 ; \mathrm{p}<0.001)$ with insignificant treatment effect $(\mathrm{F}(1 ; 38)=0.02$; $\mathrm{p}=0.87)$ and significant interaction $(\mathrm{F}(7 ; 38)=4.25 ; \mathrm{p}<0.001)$. The pattern of the results is quite diverse. Highest values were given by landrace no. 16 in both treatments, but the values are significantly higher only from landrace no. 19 and 8, respectively. In case of landrace 8 and 11 significant increases were observed for the cleaned treatment. Landrace 16 and variety 21 showed no difference over treatment, while the other traits gave lower results when cleaned. The decrease was significant only in case of landrace no. 20. No conclusions can be drawn from the data observed, but increase of TA is more likely. However, it should also be mentioned, that differences between treatments within a trait are very low in every case. 


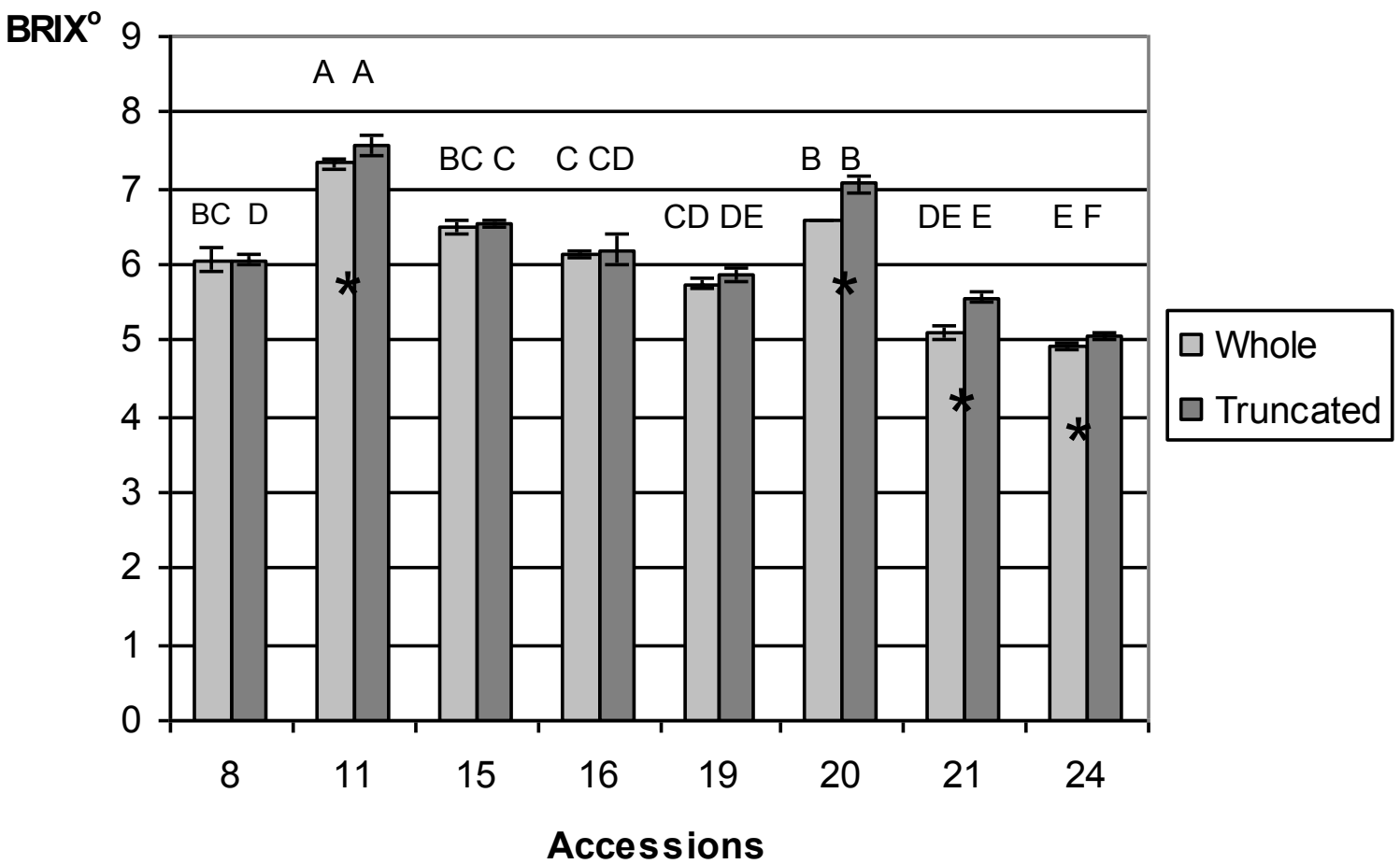

Figure 1 Total soluble solids (TSS) levels of investigated accessions before (grey) and after removing disordered parts (black) Different letters on columns show significant differences between varieties on the $\mathrm{p}<0.05$ level, according to Games-Howell's post hoc test.

* significant differences between treatments on the $\mathrm{p}<0.05$ level.

Considering lycopene content (Figure 3), we detected that the effect of varieties is significant $(F(7 ; 38)=20.42 ; p<0.001)$ with insignificant treatment effect $(F(1 ; 38)=0.76 ; p=0.39)$ and significant interaction $(\mathrm{F}(7 ; 38)=6.78 ; \mathrm{p}<0.001)$. Lycopene content of landraces no. 11, 16 and 20 were outstanding in both treatments reaching $12.66,9.73$ and $7.77 \mathrm{mg} / 100 \mathrm{~g}$ values without cleaning, respectively, and 8.66, 7.1 and $12.66 \mathrm{mg} / 100 \mathrm{~g}$ after cleaning, respectively. These accessions are therefore suggested for further analysis and for utilization by plant breeding to enhance lycopene levels of future varieties. Impact of treatments showed an increase in five cases, while in three cases a decrease was observed between treatments. Note that the variances were very high which made significant treatment effect difference detection impossible.

Table 2 summarizes the changes of three investigated parameters and of calculated values. The ratio between soluble solids and acids as well as flavor intensity changed in every case. With the exception of landraces no. 8 and 11 the ratio is higher in case of cleaned samples than without treatment. Based on flavor intensity changes landraces no. 8, 11 and variety 21 show considerable increase, while the others show a little positive or negative change. The exception is variety 24 , which has a decrease in FI over cleaning. 


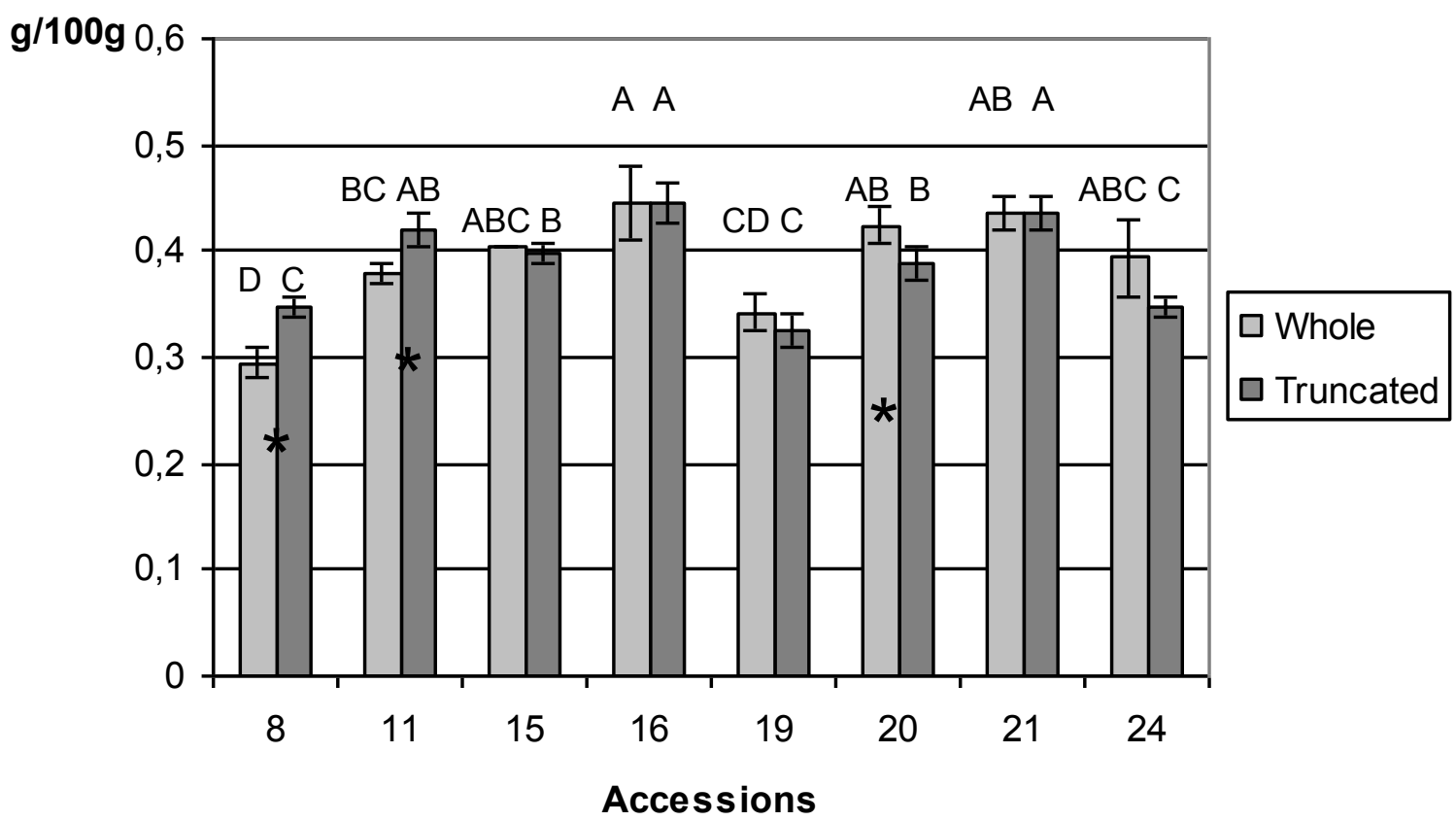

Figure 2 Total acid (TA) content of investigated accessions before (grey) and after removing disordered parts (black). Different letters on columns show significant differences between varieties on the $\mathrm{p}<0.05$ level, according to Games-Howell's post hoc test. * significant differences between treatments on the $\mathrm{p}<0.05$ level.

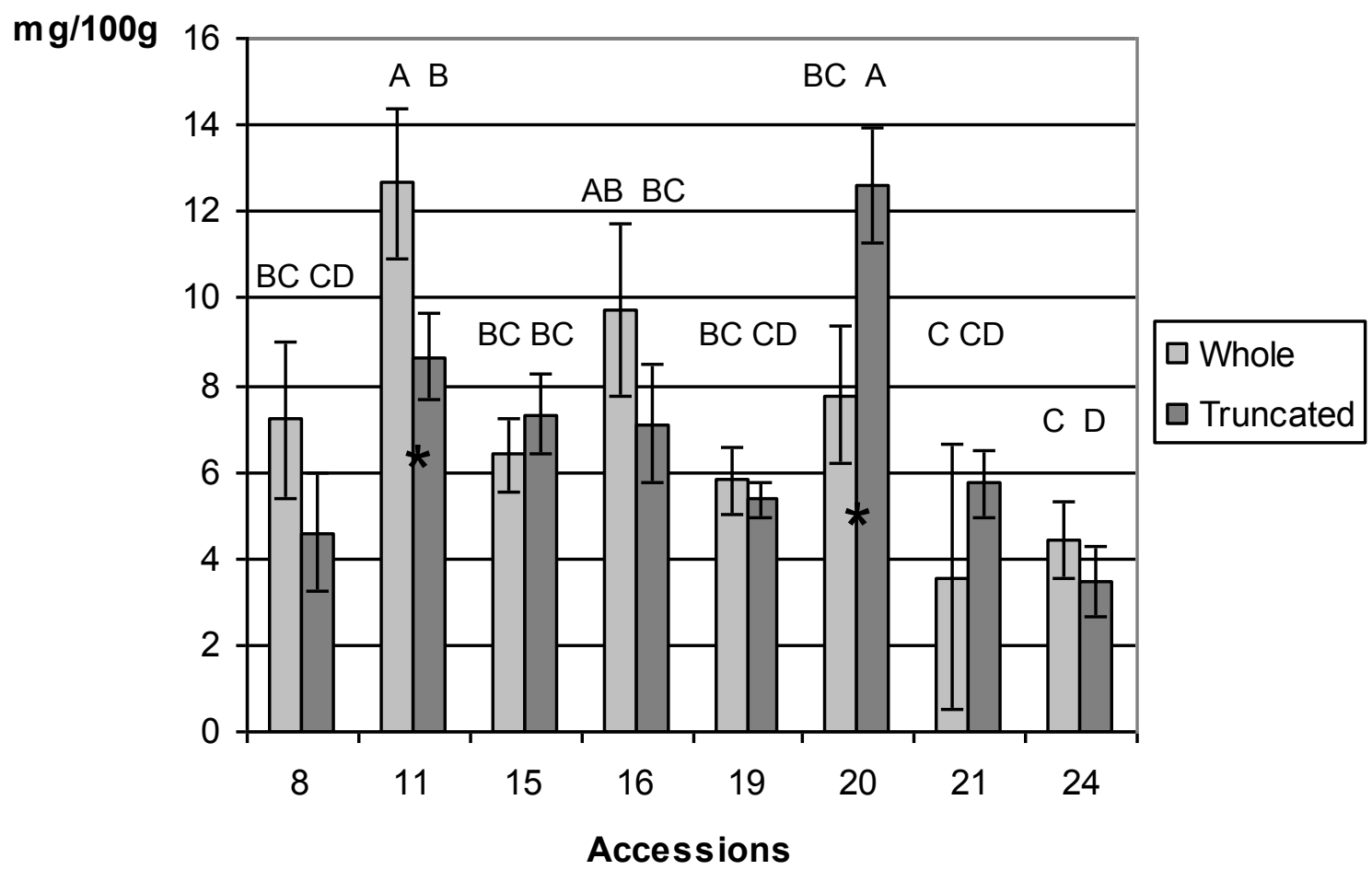

Figure 3 Lycopene content changes of investigated accessions before (grey) and after removing disordered parts (black). Different letters on columns show significant differences between varieties on the $p<0.05$ level, according to Games-Howell's post hoc test.

* significant differences between treatments on the $\mathrm{p}<0.05$ level. 
Table 2 Differences between investigated parameters of untreated and cleaned samples within an accession/variety. Asterisks indicate $p \leq 0,05$, plus sign indicates $p \leq 0,1$ significance level.

\begin{tabular}{|l|l|l|l|l|l|}
\hline Variety & TSS & TA & Lycopene & TSS/TA & FI \\
\hline 8 & 0,00 & $0,05^{*}$ & $-2,59$ & $-3,07$ & 0,31 \\
\hline 11 & $0,23+$ & $0,04^{*}$ & $-4,00^{*}$ & $-1,36$ & 0,40 \\
\hline 15 & 0,03 & $-0,01$ & 0,92 & 0,29 & $-0,02$ \\
\hline 16 & 0,07 & 0,00 & $-2,62$ & 0,15 & 0,03 \\
\hline 19 & 0,12 & $-0,02$ & $-0,43$ & 1,16 & $-0,05$ \\
\hline 20 & $0,47^{*}$ & $-0,04^{*}$ & $4,83^{*}$ & 2,65 & $-0,06$ \\
\hline 21 & $0,47^{*}$ & 0,00 & 2,18 & 1,07 & 0,20 \\
\hline 24 & $0,13^{*}$ & $-0,05$ & $-0,96$ & 2,07 & $-0,18$ \\
\hline
\end{tabular}

It can be concluded that in case of investigated six landraces and two varieties removal of abiotically disordered fruit parts have an impact on TSS, TA and lycopene content. However, the present study could demonstrate the relatively lower TSS content of disoredered parts within a tomato fruit. This difference was significant in case of landraces 11,20, and varieties 21, 24. Impact of cleaning on TA is rather low. As a conclusion removal of disordered parts can enhance both TSS/TA ratio and FI, which can develop the flavor of processed products, but reduce the volume of it with an average of 30 percent in case of investigated accessions and varieties.

\section{REFERENCES}

Abushita, A.A., Hebshi, E.A., Daood, H.G., Biacs, P.A., 1997. Determination of antioxidant vitamins in tomatoes, Food Chemistry 60 (2) 207-212

Casals, J., Pascual, L., Canizares, J., Cebolla-Cornejo, J., Casanas, F., Nuez, F., 2011. The risks of success in quality vegetable markets: Possible genetic erosion in Marmande tomatoes (Solanum lycopersicum L.) and consumer dissatisfaction. Scientia Horticulturae 130, 78-84

Davies, J.N., Hobson, G.E., 1981. The constituents of tomato fruit - The influence of environment, nutrition and genotype. Critical Reviews in Food Science and Nutrition, 15 (1) 204-280.

Giovannucci, E., 1999. Tomatoes, tomato-based products lycopene and cancer: review of epidemiological literature. Journal of National Cancer Institute 91, 317-331

Male, C.J., 1999. 100 Heirloom Tomatoes for the American Garden. Smith \& Hawken, 27

Powell, A.L.T., Nguyen, C.V., Hill, T., Cheng, K.L., Figueroa-Balderas, R., Aktas, H., Ashrafi, H., Pons, C., Fernández-Munoz, R., Vicente, A., Lopez-Baltazar, J., Barry, C.S., Liu, Y., Chetelat, R., Granell, A., Van Deynze, A., Giovannoni, J.J., Bennett, A.B., 2012. Uniform ripening Encodes a Golden 2-like Transcription Factor Regulating Tomato Fruit Chloroplast Development, Science 29 (336) 6089, 17111715

Rodrigúez-Burruezo, A., Prohens, J., Roselló, S., Nuez, F., 2005. „Heirloom” varieties as sources of variation for the improvement of fruit quality in greenhouse-grown tomatoes, Journal of Horticultural Science \& Biotechnology 80 (4) 453-460

Stevens, M.A., 1970. Relationship between polyene-carotene content and volatile compound composition of tomatoes. Journal of the American Society for Horticultural Science 95, 461-464. 